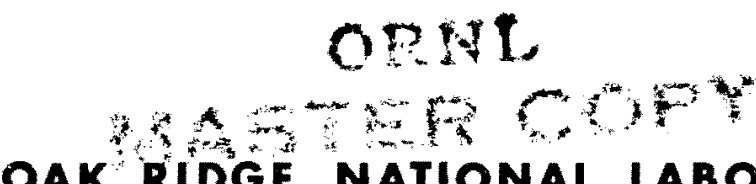

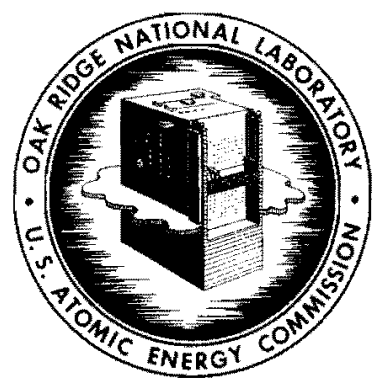

OAK RIDGE NATIONAL LABORATORY

operated by

UNION CARBIDE CORPORATION

NUCLEAR DIVISION

UNION

for the

U.S. ATOMIC ENERGY COMMISSION

ORNL - TM- 364

OPERATIONAL SAFETY AND RADIATION PROTECTION FOR THE OAK RIDGE ISOCHRONOUS CYCLOTRON

J.A. Russell, Jr., and R. J. Jones

NOIICE This document contains information of a preliminary noture and was prepared primarily for internal use of the Oak Ridge National Laborotory. It is subject to revision or correction and therefore does not represent a final report. 
This reporf was prepared as an account of Government sponsored work. Neither the United States, nor the Commission, nor ony person aeting on behalf of the Commission:

A. Makes any warranty or representation, expressed or implied, with respect to the accuracy, completeness, ar usefulness of the information contained in this report, or that the use of any informotion, opparatus, method, or process disclosed in this report may nof infringe privately owned rights; or

8. Assumes any liabilities with rospect to the use of, of for domoges resulting from the use of any information, apparatus, mothod, or process disclased in this report.

As used in the above, "person acting on behalf of the Cammission" includes any employee or contractor of the Commission, or employe of such contractor, to the extent that such employee or contractor of the Commission, or employes of such contractor prepares, disseminates, or provides access to, ony information pursuant to his omployment or contract with the Commission, or his employment with such contractor. 
Contract No. W-7405-eng-26

ELECTRONUCLEAR DIVISION

\title{
OPERATIONAL SAFETY AND RADIATION PROTECTION FOR THE OAK RIDGE ISOCHRONOUS CYCLOTRON
}

J. A. Russell, Jr., and R. I. Jones

\author{
October 1962 \\ Revised \\ October 1966
}

\section{NOVEMBER 1966}

OAK RIDGE NATIONAL LABORA TORY

Oak Ridge, Tennessee

operated by

UNION CARBIDE CORPORATION

for the

U.S. ATOMIC ENERGY COMMISSION 
.

- 
OPERATIONAL SAFETY AND RADIATION PROTECTION

FOR THE OAK RIDGE ISOCHRONOUS CYCLOTRON

J. A. Russell, Jr., and R. J. Jones

\begin{abstract}
Two independent systems for providing operational safety and radiation protection for personnel at the Oak Ridge Isochronous Cyclotron are described in detail. A radiation alarm system monitors all hazardous areas. The cyclotron and all beam-use areas are operated completely by remote control; a complex system of interlocks and operation controls prevent access to any hazardous area while the cyclotron is in operation. This system is designed so that at least three interlocks must fail and both the person entering the room and the operator must make mis judgments before a radiation exposure can occur. In four years of cyclotron operation the systems have proved fully reliable and operationally very satisfactory.
\end{abstract}

\title{
INTRODUCTION
}

This report describes the radiation alarm and interlock systems for the Oak Ridge Isochronous Cyclotron, Building 6000. Two independent systems are provided: (1) a radiation alarm system to warn personnel when a hazardous condition exists, and (2) an interlock system to prevent access to any dangerous area while the cyclotron is in operation. The alarm system provides both audible and visual signals at dangerous radiation levels and does not incorporate any interlock function with either the cyclotron or shield-door drawbar mechanisms. The system of safety interlocks prevents operation of the cyclotron if shield-wall plugs and shield-doors are in an unsafe position. An unsafe condition exists whenever any access opening from the cyclotron or target to inhabited areas is not closed. The system is designed so that at least three interlocks must fail and both the person entering the room and the operator must make misjudgments before a radiation exposure can occur. 


\section{RADIATION MONITORING SYSTEM}

\section{Building Usage}

The facilities include offices, laboratories, hot laboratories, shop areas, and radiation experimentation areas. The building has been divided into two zones: Zone 1, Radiation Areas; and Zone 2, Non-Radiation Areas.

Radioactive materials are kept or handled only on the first floor; this Zone 1 includes the shielded areas, the shop, and the four laboratories on the south corridor. As a guard against accidental removal of radioactive material from Zone 1 , monitors are located at all exits. Alarms are set to provide audible alarms at hazardous levels.

Zone 2 includes all areas in the building where radioactive materials are not permitted. These areas are checked for contamination regularly by Health Physics surveys.

The cyclotron vault and experiment Room C-110 are intended primarily for nuclear physics experimentation. The radiation in these areas is due to the high energy beams; activity after shutdown rapidly decreases to near tolerance levels. Room C-111 is used for producing isotopes and for bombarding chemical targets. Targets which present a potential alpha hazard conform to double-containment safety standards. The laboratories are provided with filtered exhaust hoods which are used whenever there is a possibility of the release of airborne contamination.

\section{Radiation Instrumentation}

The instruments designed and stocked specifically for personnel monitoring are described in detail in Appendix $I$.

A Model Q-1939B beta-gamma radiation detector for checking hands and feet for radioactive material is located in the shop area between the shielded doors. A second unit is located in the hallway outside Room C-111. These locations are designated $\mathrm{H}$ on Fig. 1. 


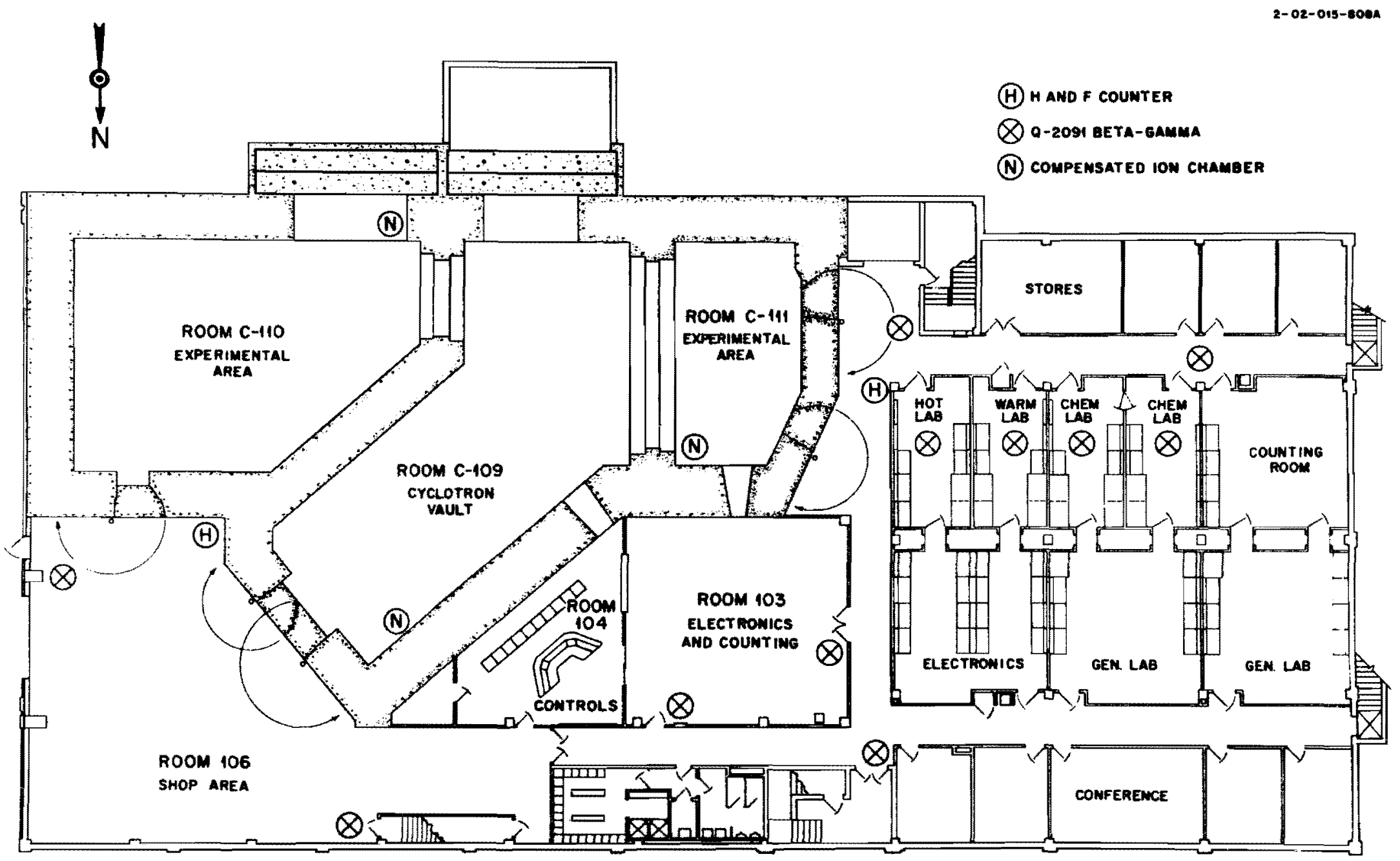

Fig. 1. ORIC First-Floor Plan showing locations of radiation monitoring instruments. 
Model Q-2091 linear count rate meters with beta probes are located at exits from the radioactive work area and hot laboratories as designated $\mathrm{X}$ on Fig. 1 .

The three exhaust ducts from the shielded areas are equipped with Model Q-2240 beta-gamma constant air monitors to guard against discharge of contaminated material from the stacks. These units activate an alarm in the control room.

Each laboratory in which radioactive material is handled is equipped with an air sampler which collects dust on a filter paper. The filter is checked at periodic intervals by Health Physics or Electronuclear Division personnel. Two portable alpha continuous air monitors (Model Q-2340) are available for use in high level alpha handling work of a temporary nature. An ac-operated alpha detector (Q-2091 with alpha probe for manual surveying) is mounted near the exhaust hoods in each laboratory where it is expected that alpha handling will be routine. The probe is on a cable long enough to reach inside the exhaust hood.

A beta-gamma continuous air monitor (Model Q-2240) is located in the building for use in any area where the regularly installed continuous air monitors are not effective. Four Model Q-2091 linear count rate meters with alpha probes are located as shown in hallways near the entrance to the shielded rooms and in the chemical laboratories and counting room.

For counting smears taken on components suspected of having transferable radioactivity two instruments are available: a thin-window geige $r$ counter for beta-gamma activity and a scintillation detector for counting alpha activity. Both detectors are connected to scalers.

Experience has shown that the following list of portable instruments is sufficient to provide routine survey service:

10 "Cutie pie" beta-gamma detectors

6 Portable GM survey meters

2 High range "cutie pie" meters

2 Portable alpha monitors (Q-1975 with Q-2101 Probes) 
1 Portable fast neutron monitor

1 Portable thermal neutron monitor

Most of these instruments are pictured and described in the ORNL Radiation Safety and Control Training Manual. Except for the standard "cutie pie" beta-gamma detectors (10 rad/hr max) and the portable GM survey meters, the portable meters are all kept in a central location. The standard "cutie pie" and the GM survey meter are available outside each of the shielded rooms and in areas where radioactive materials are used.

\section{Special Systems}

The neutron levels in the cyclotron room and in experiment rooms are measured with a compensated ion chamber. Chamber output current is measured continously on a micromicro-ammeter in the control room. The neutron and gamma level in the cyclotron vault is monitored continuously and recorded. Readings can be extended over approximately $7-1 / 2$ decades by adjusting the range of the instruments. The instruments are located at the points marked $N$ on Fig. 1.

A Q-2191 (Model Q-2091 with integrally mounted recorder) count-rate meter with a gamma-sensitive probe is used to monitor activation of the demineralized water 'hot" circuit. The probe is strapped to the return line (WHD-102-4") where demineralized water enters the equipment area. This instrument operates an annunciator at the control panel in case of high activity in the demineralized water.

\section{Communications}

The building is equipped with a 15-station intercom system. These telephones are located inside each shielded room, just outside each shield-door, and in the control room. They also connect to the laboratories and to the third-floor utility area. There is also a paging system which can be operated from the control room, the main office, the development area, and from stations in the over-all plant protection system. For emergency use there are Bell phones in each of the shielded rooms. The most frequent use of the communications system is the coordination of operation and maintenance procedures. 
OPERATIONAL SAFETY AND INTERLOCK SYSTEM

\section{Types of Hazard}

Two types of radiation hazards are encountered as a result of cyclotron operation.

(1) Residual activity of equipment and targets after the cyclotron is shut down.

(2) High energy beam and ensuing scatter from targets under bombardment.

Overexposure due to working with radioactive materials is avoided by careful monitoring, limiting the exposure time and by employing long-handled tools and localized shielding.

While the machine is in operation personnel are protected from the high energy primary beam and secondary radiation from a target during bombardment by shield-doors, shield-wall plugs, and interlock switches which prevent access to rooms containing the cyclotron beam. A selector switch connects the proper interlocks into the high voltage control system for any one of nine predetermined target locations.

\section{Installed Protection Systems}

\section{Block Diagram}

A block diagram of the protective interlock is shown in Fig. 2.

\section{Target Station Selection Switch}

There is one target station in the cyclotron vault, three in experiment Room $\mathrm{C}-110$, and five in experiment Room $\mathrm{C}-111$. A selector switch on the console is used to select from these nine target stations the one to be used. This selection of a target station automatically connects that particular set of interlocks which makes it possible to deliver the beam to the selected station, but to no other, and at the same time permits safe access to stations in both experiment rooms if the vault station is being used, or to stations in one experiment room if the other is being used.

If a target station is selected in Room C-111, then the following conditions must exist before the rf high voltage can be turned on: 


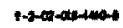

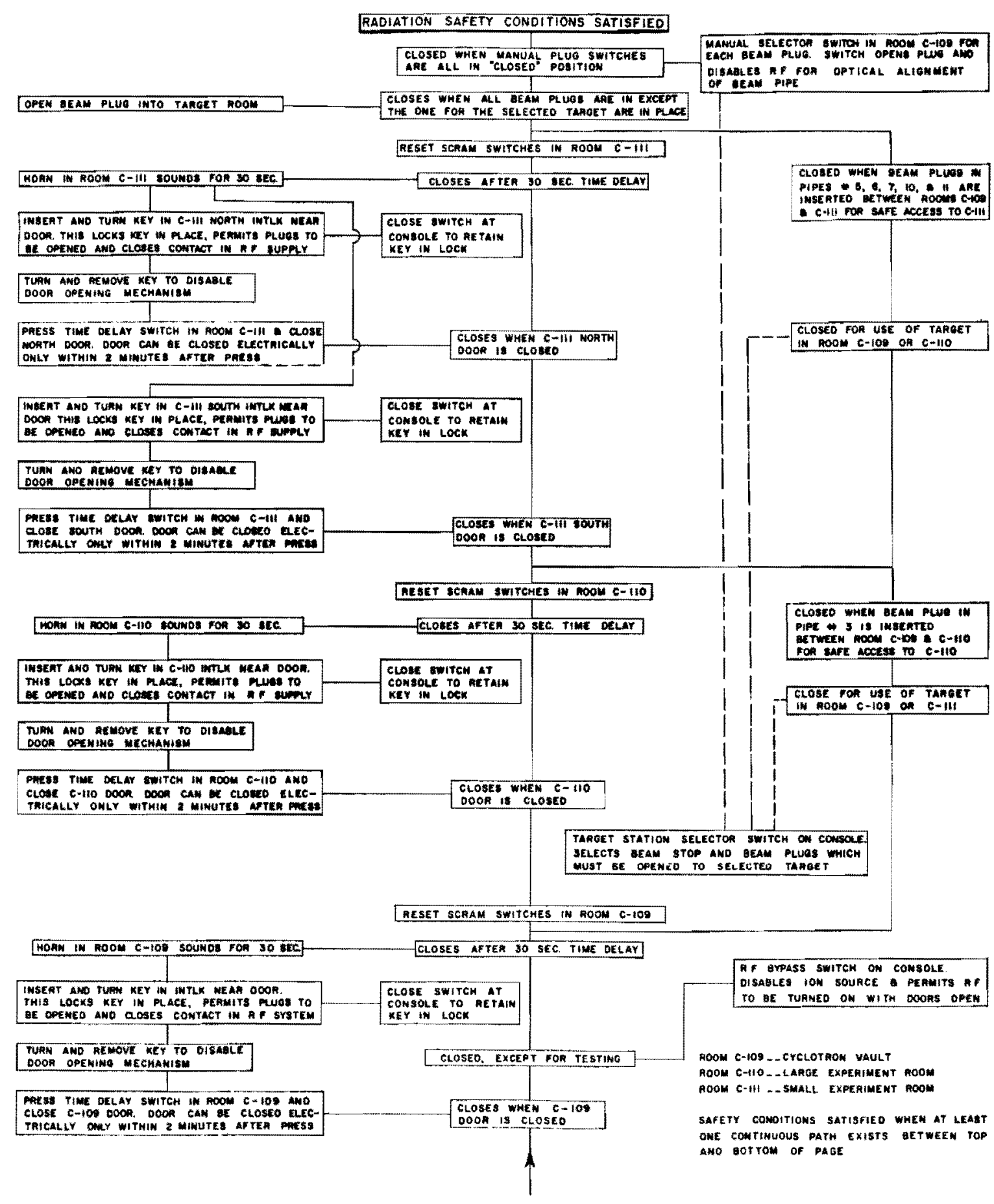

Fig. 2. Radiation Safety Interlock Diagram. 
(1) The radiation shielding doors must be closed to both the cyclotron vault and the Room C-111. (2) The shield-wall plug must be in place between the cyclotron room and Room C-110, or Room C-110 shielding door must be closed. (3) The keys to Room C-111 and to the cyclotron vault doors must both be in the $\mathrm{rf}$ high voltage key interlocks (described later) mounted on the outside wall of Room C-11l and on the cyclotron vault respectively.

If a target location is selected in experiment Room C-110, the same situation exists except Room C-111 and Room C-110 are interchanged.

If a target station in the cyclotron vault is selected, then the following conditions must exist before the rf high voltage can be turned on: (1) The shielding door to the cyclotron vault must be closed and the key to the rf high voltage interlock inserted. (2) The shieldwall plugs must be in place between the cyclotron vault and Rooms C-110 and C-111, or Room C-110 and/or Room C-111 shielding doors must be closed, and the associated key interlocks in the "operate" position.

Illuminated signs are located above or beside the shielding doors leading into each experiment room, with black letters on a red translucent background stating "Selected Target Inside." A similar sign inside each room states "Selected Target This Room."

\section{Key Interlocks}

The four radiation shielding doors each have a separate key interlock system. Four permissive switches are located on the console, one for each $\mathrm{rf}$ high voltage key interlock; the proper switch must be "on" before the key can be removed from the rf high voltage key interlock adjacent to the door. The target selector switch determines which door key interlock circuits are connected into the $\mathrm{rf}$ high voltage permissive circuit. The system consists of two locks and one key. One of the locks is mounted on the wall near the shielding door. If a target station has been selected in one of the rooms, removal of the key from the lock on the wall for that room inserts the shield-wall plugs in beam pipes entering that room and opens the rf high voltage 
permissive circuit, which prevents the dee voltage from being turned on. The other lock is mounted on the door; the insertion of the key in this lock energizes the door drawbar mechanism and makes it possible to open the door electrically.

Any shield door can be opened manually by operating the hand wheel in case of power failure or emergency.

Either experiment room may be entered while the cyclotron is running if the selected target station is located in the other experiment room or in the cyclotron vault and if all shield-wall plugs into that room are in place.

Shielding Door Controls

The shielding door latch mechanism can be operated electrically from the outside to open or close the door only after the key has been inserted in the interlock on the door. Further, before the push button for opening the door will function a warning must be sounded with in the room. Pressing a permissive button inside the shielded room on the far wall opposite the door sounds a horn and starts a timing sequence which allows a period of two minutes during which the door closing sequence can be initiated. If the closing sequence has not been started within two minutes, the permissive button must again be operated before the door can be closed electrically. The door can be closed manually at any time.

An emergency mushroom-head button located on the inside of each shielding door can be used at any time to energize the door control circuit and start the door opening operation, which always opens a contact in the high voltage interlock circuit. This button also overrides any electrical door action which has been started from the outside (including the interlock key). Thus, even after the closing mechanism is in action, anyone trapped on the inside can still push this "scram" button on the inside of the door and start the door opening.

\section{Shielding Door Switches}

Each shielding door has three interlock switches that are closed when the door is completely closed. One of the switches is 
in the rf high voltage permissive circuit so if the door is open, the rf high voltage cannot be turned on.

The second switch, in the same circuit as the first, is at the side of the door and is opened when the interlock key is removed. The key can be removed from the door interlock unit only when the door is fully closed. Thus, the key interlock on the wall cannot be closed; and, therefore, the rf high voltage cannot be turned on.

The third switch is in parallel with the shield-wall plug switch and opens if the door is opened. The $\mathrm{rf}$ high voltage circuit breaker cannot be closed if both door and beam port of any room are open.

\section{Shield-Wall Plugs}

Beam ports with shield-wall plugs are located in the walls between the cyclotron vault and each of the experiment rooms to reduce radiation leakage from one room to another. In operation all shield-wall plugs are inserted except the one through which the beam is directed. When a shield-wall plug is closed, the beam stop immediately ahead of it in the beam pipe is also closed. When a key is removed from the key interlock adjacent to the door into any shielded room, any shield-wall plug that is open between the cyclotron vault and that experiment room closes automatically. An over-ride control is provided in the cyclotron vault to permit opening any shield-wall plug whenever the door into the cyclotron vault is open. Each of these plugs has four switches that close when the plug is in place. One switch is in the rf high voltage permissive circuit. A second switch is in the rf high voltage circuit breaker circuit. A third switch is a light circuit displayed on the control panel. A fourth switch is in the shielding door latch circuit and must be closed before the door can be opened electrically.

Beam Stops

Beam stops are located at the front of each beam pipe valve and are intended to intercept and absorb all the beam energy. They protect valves and shield-wall plugs in case of malfunction of any part of the system. The beam stop opens automatically whenever 
the shield plug and the valve are opened. All beam stops on pipes leading into an experiment room close when the key interlock is removed from the wall unit for that room.

Scram Buttons

Mushroom type "scram" buttons are mounted around the walls inside all shielded areas. These buttons open the rf high voltage permissive circuit. A mushroom type "scram" button is also mounted on the inside of each door. Its function is described under "Shielding Door Control."

\section{Test Interlocks}

A switch is located on the control console for bypassing the rf high voltage interlocks and for de-energizing the ion source arc voltage supply. This switch permits testing the radio frequency system with the shielding doors open while the ion source is inactive.

Alarms and Annunciators

A klaxon horn is located inside each shielded room. The horn sounds when a warning switch inside the room is depressed and also for a 20-sec period after the door to that area is closed. If the station selector switch is set to a station in that room, then the rf high voltage permissive circuit remains open for the same 20 seconds.

An illuminated sign located above or beside each shield door indicates the following:

(1) Target Selected Inside - Described on page 6.

(2) RF On - Black letters on red translucent background - lights up when $r f$ voltage is applied to the dee.

(3) Beam Port Closed - (Installed only at each experiment room door.) Black letters on yellow translucent background - lights up when shieldwall plugs to that room are closed, and it is safe to enter, with caution.

At the cyclotron vault door sign No. 3 is "Source On" sign with black letters on a translucent yellow background.

These indicators are repeated inside the shielded rooms.

Three red illuminated "Magnet On" signs are located in the cyclotron vault in the vicinity of the magnet. When the main magnet generator is rotating, the lights flash about 30 times a minute 


\section{OPERATING ROUTINES}

Entry to Shielded Area

To enter a shielded room permission must be obtained from the operator. The operator then closes the beam plugs and releases the key in the rf high voltage key interlock by closing the appropriate permissive switch. (Only the cyclotron operators have keys to the permissive switches.) The person entering removes the interlock key from the wall unit and inserts it in the door key interlock and pushes the "open" button on the door.

The accidental opening of a shield door while the beam is still in the room requires the misjudgment of the operator and of the person entering, and the failure of three circuits. (The key interlock and two door switches, one of which is in parallel with a beam plug contact.)

\section{Placing Cyclotron in Operation}

In preparation for cyclotron operation the operator enters each shielded room that has been opened and (1) checks to see that no one is inside, (2) checks all "Scram" buttons to see that they are in the "Operate" position, (3) presses the door closing permissive button at the far end of the room, (4) operates the electrical door closing switch within two minutes, and (5), after the shield door is closed, removes the interlock key from the door lock and inserts it in the wall lock and turns it to the "Operate" position.

In the control room the interlock key release switch, the target selector switch, and the rf interlock bypass should be in their operating positions. Shield-wall plugs, beam stops, beam and vacuum valves, and cooling water circuits to all components in the selected beam path should be in the "On or Open" position. All brightly lighted indicators on the control panel should be illuminated green. The machine is now ready for operation; the $\mathrm{rf}$, ion source, and magnet power may be applied in the normal manner. 


\section{EDITOR'S NOTE}

This document was prepared originally in 1962, before the ORIC was actually operating. Operating experience during the past 4 years has shown the radiation protection system to be reliable and very satisfactory. Only minor changes have been made in the text to make it agree with current practice. 
APPENDIX I. Radiation Instruments

The Model Q-1939B is an ac-powered, four-channel monitor for beta-gamma radiation with a channel for each hand, a channel for the shoes, and a channel with a movable probe. The probe, which is mounted about waist high for monitoring the front of the operator's clothing at waist level, may also be usedas a survey probe for localizing high radiation levels on hands, clothing, shoes, etc. Three channels are identical modular units, actuated by a halogenquenched stainless steel wall GM tube. The counting rate is indicated by glow transfer tubes and electrical reset registers. The fourth channel used in conjunction with the survey/background probe is a modular constructed aural monitor channel actuated by a halogenquenched stainless steel wall GM tube. A push button starts the time cycle, after which operation is automatic. The instrument resets itself and, after a 4-sec "get ready" period, counts for 24 sec; the total cycle takes 30 seconds. The maximum count rate per channel is 100 counts per second, except for the survey probe channel where 5,000 counts per second will produce a steady tone and 10 counts per second can be perceived. The input resolving time of all channels is about 200 microseconds. The instrument is contained in a rack cabinet 68-3/8 in. high $\times 21-1 / 16$ in. wide $\times 22$ in. deep. A detachable base 4 in. high $\times 18$ in. long $\times 21$ in. wide contains the foot monitor as sembly. Power requirements are $115 \mathrm{~V} \pm 10,60 \mathrm{cps}, 75 \mathrm{~W}$ and 0.7 ampere.

The Model Q-2091 is a linear, duty-cycle type count rate meter which includes an amplifier, a high voltage supply, a high level alarm circuit, an aural monitor, and a one-milliamp full-scale output suitable for recording or telemetering. The instrument employs vacuum tube circuitry and is powered from the $115-\mathrm{V}, 60-$ cycle line. It is designed for use with a GM tube or an alpha scintillation detector. The unit is packaged in a cabinet about 8 in. wide, $9 \mathrm{in.} \mathrm{high,} \mathrm{and}$ 12 in. deep. 
It has an input sensitivity to negative pulses of $200 \mathrm{mV}$; linearity of $2-1 / 2 \%$, long term accuracy of $5 \%$. A $900-\mathrm{V} 20-\mu \mathrm{A}$ regulated supply is built into the instrument. Rarige settings of 250, 1000,2500 , 10,000 , and 25,000 counts per minute, and integrating time constant of 1,11 , and 21 sec are available at front panel selectors. The instrument has an aural signal proportional to counting rate and contacts for remote alarm. The alarm contacts of each instrument are connected to lamps on a small graphic display in the control room to show the operator which radiation detectors are in the alarm condition.

The Model Q-2240 beta-gamma constant air monitor is a package system consisting of an air-aspirating system, paper filter tape, thin wall halogen GM tube, linear count rate meter, recorder, visible and aural alarms. The air system consists of a Roots blower with an electric motor and vee-belt drive. The particulate sample is collected on filter paper tape that is advanced on a step-wise basis. The detector counts the sample as it is being collected. The GM detector has a thin-wall metal shell with a thickness of $30 \mathrm{mg} / \mathrm{cm}^{3}$. It is enclosed in a stainless steel shield having a wall thickness of two inches and is situated so that the detector monitors the dust collected on the filter tape. The count rate meter is a linear dutycycle type meter with a single range of 5,000 counts per minute, full scale. The high voltage supply is an integral part of the rate meter. The rate meter has a "Caution" alarm adjustable from 2 to $58 \%$ of full scale and a high level alarm adjustable from the caution level set point to full scale. There is a $1-\mathrm{mA}$ full-scale signal for operation of a "Rustrak" recorder. 

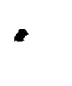

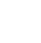

, 
ORNL-TM-364

\section{INTERNAL DISTRIBUTION}

1. J. E. Bentley

2. A. L. Boch

3. N. E. Bolton

4. C. J. Borkowski

5. F. R. Bruce

6. H. M. Butler

7. J. A. Cox

8. H. L. Dickerson

9. E. L. Earley

10. E. P. Epler

11. J. L. Fowler

12. C. B. Fulmer

13. J. H. Gillette

14. E. D. Gumpton

15. C. S. Harrill

16. F. T. Howard

17. T. W. Hungerford

18. J. W. Johnson

19. B. H. Ketelle

20. R. S. Livingston

21. R. S. Lord

22. L. O. Love

23. H. G. MacPherson

24. F. Maienschein
25. M. L. Mallory

26. F. W. Manning

27. M. B. Marshall

28. C. D. Moak

29. W. F. Ohnesorge

30. G. A. Palmer

31. A. W. Riikola

32. J. A. Russell

33. A. H. Snell

34. P. H. Stelson

35. L. A. Slover

36. E. W. Sparks

37. W. R. Smith

38. S. S. Stevens

39. C. L. Viar

40. A. M. Weinberg

41. A. Zucker

42-43. Central Research Library

44. Document Reference Section

45-47. Laboratory Records

48. Laboratory Records - RC

49. ORNL Patent Office

50-99. Laboratory Records

100-150. Accelerator Information Center

EXTERNAL DISTRIBUTION

151. Resea $\mathrm{rch}$ and Development, ORO

152-167. Division of Technical Information

Extension, OR

168. Howard Heacker, AEC 


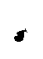

,

1 - 